\title{
GUARANÁ ORGÂNICO: ECODESENVOLVIMENTO E COMÉRCIO JUSTO
}

\author{
GUARANA ORGANIC: FAIR TRADE AND GREEN DEVELOPMENT
}

Recebido em: 31/07/2013 Aprovado em: 27/09/2013
Avaliado pelo sistema double blind review
Editora Científica: Manolita Correia Lima

\begin{abstract}
ADRIANA TEIXEIRABASTOS adriana@ead.uece.br CORA FRANKLINA DO CARMO FURTADO UNIVERSIDADE ESTADUAL DO CEARÁ
\end{abstract}

FÁTIMA REGINA NEYMATOS

UNIVERSIDADE DE FORTALEZA

MÁRIO HENRIQUE OGASAVARA

ESCOLA SUPERIOR DE PROPAGANDA E MARKETING

\begin{abstract}
RESUMO
O objetivo do caso de ensino é apresentar o Projeto Wará, que desenvolve uma produção sustentável no sentido de agregar valor para os consumidores. O caso descrito ilustra o dilema entre a possibilidade de ampliação de atividade econômica, tendo como pano de fundo os negócios internacionais e questões éticas e culturais que levam em consideração não somente a sustentabilidade econômica, mas principalmente a ambiental e a social. Trata-se de uma história complexa, pois incorpora elementos de diferentes áreas do conhecimento, como estratégia internacional, desenvolvimento sustentável, ética e organização social. O questionamento principal a ser trabalhado no caso de ensino é identificar como o Consórcio dos Povos Aisó Ayira, responsável pelo Projeto Wará, pode proteger a produção da concorrência, que oferece um produto semelhante e mais barato, para garantir a sua sustentabilidade.

Palavras-chave: sustentabilidade; comércio justo; guaraná; índios da Amazônia; comércio internacional.
\end{abstract}

\footnotetext{
ABSTRACT

This case presents the Wará Project, which develops sustainable production in harmony with nature in order to add value and educate consumers, as well as ensure production for present and future generations (WCED, 1991). The case illustrates the dilemma between possible economic growth against the backdrop of international business and ethical and cultural issues, which take into account not only economic sustainability, but primarily environmental and social sustainability. This comprises a complex story, as it incorporates elements from various areas of knowledge, such as international strategy, sustainable development, ethics and social organization. The main issue for discussion in this teaching case is the identification of how the Consortium Peoples Aisó Ayira, responsible for Project Wará, can protect against the competition, which offers a similar, cheaper product, to ensure their sustainability.

Keywords: sustainability; fair trade; guarana; Amazonian Indians; international trade.
} 


\section{INTRODUÇÃO}

Moaci está na Vila de Guaranatuba, no Rio Andira, Estado do Amazonas, em um dia claro de 2004, ouvindo mais uma vez a estória que D. Iara, produtora de guaraná, costuma contar sobre a origem do guaraná. Com voz doce e macia, ela lembra que havia na floresta uma índia que, ao saber que estava grávida, decidiu plantar uma castanheira para que seu filho quando estivesse grande pudesse comer dos seus frutos. Entretanto, quando o menino já estava crescido e a castanheira produzindo frutos abundantemente, os tios da criança, por inveja, decidiram seguir a criança e espancá-la até a morte. A mãe, ao encontrar o rapaz morto, retirou os olhos dele e os plantou, profetizando que deles nasceria uma planta que se espalharia pelo mundo todo e que seria muito amada e respeitada nos quatro cantos da terra.

Enquanto espera pelos líderes das tribos e organizações parceiras para analisar e decidir o futuro do Projeto Wará, Moaci imagina que o guaraná surgiu predestinado para ganhar o mundo.

Moaci idealizou o projeto há 18 anos e sempre soube que não era objetivo do projeto deixar o produtor rico da noite para o dia. A sustentabilidade econômica, ecológica e social sempre foi a principal proposta, afinal, os integrantes da tribo assumiram que as gerações anteriores tinham se engajado a um sistema de mercado que poderia levar à destruição da floresta Amazônica e a sua geração não podia incorrer nesse erro novamente. Moaci e a tribo acreditavam que o ecodesenvolvimento só poderia acontecer se a produção respeitasse a natureza, o homem e a sociedade. Este era o conceito de sustentabilidade para eles. Não adiantava produzir o guaraná, exportar e ganhar dinheiro se não proporcionasse o desenvolvimento sustentável.

A luta foi difícil, no início, reuniam-se as famílias de produtores indígenas como sujeitos autônomos dentro da sociedade Aisó Ayira e na economia mundial, respeitando a cultura tradicional comunitária e o papel da produção coletiva de renda econômica. Também, foram vencidos os entraves com a grande indústria do guaraná, que tentava disseminar uma forma pouco natural de produção em nome da produtividade. 
Hoje, depois de superado estes desafios iniciais, a realidade é outra. Os líderes estão se reunindo para definir qual o caminho a percorrer, agora que a concorrência está baixando cada vez mais o preço do produto. A cooperativa de caboclos, que há muitos anos também se fixou no Amazonas, produz guaraná orgânico em regime de monocultura e, com o aumento da produção, baixam seus preços.

Os distribuidores reivindicam ao Projeto Wará uma maior produção. Todavia é difícil, mesmo por meio do consórcio, com a produção semidoméstica, aumentar a oferta do guaraná para os níveis desejados.

Diante deste cenário, decidir como a comunidade indígena produtora de guaraná poderá se proteger da concorrência, que oferece um produto semelhante e mais barato, é o dilema que Moaci precisa resolver o mais rápido possível, pois o Projeto Wará respeita os padrões de ecodesenvolvimento e os princípios do comércio justo. 


\section{GUARANÁ, A SEMENTE DO CONHECIMENTO, DELA EMERGE O DESENVOLVIMENTO}

O Guaraná - que na língua indígena significa "o início de todo o conhecimento", é cultivado há centenas de anos na Amazônia Brasileira. Porém, somente no século xviI que foi classificado pelo botânico alemão Christian Franz Paullini como Paullinia cupana, variedade Sorbilis (SFB, 2013).

O cultivo do guaraná é muito importante para a cultura religiosa dos povos Aisó Ayira, desempenhando um papel simbólico similar ao do vinho na liturgia católica.

Os Aisó Ayira são hoje uma tribo de cerca de 8.000 pessoas que vivem em 80 aldeias no norte do Brasil. Elas cultivam o guaraná em um sistema conhecido como semi-domesticação.

Coletam as sementes que caem das árvores de guaraná na floresta, e as plantam nas clareiras, onde são aguadas pela chuva e precisam de cuidados mínimos. Na floresta, o guaraná pode crescer até I2 metros. As flores brancas das árvores crescem em longos cachos, com a forma de espigas de milho. Quando amadurecem, as flores dão lugar a cachos de frutas vermelhas, que se abrem levemente para revelar a semente preta na polpa branca. O guaraná é colhido imediatamente antes de madurecerem. [...] Após a remoção da polpa das frutas maduras, as sementes são torradas por três dias em fornos de barro tradicionais. As sementes são então descascadas, trituradas em pilão, moldadas em bastões, que pesam entre roo gramas e 2 quilos cada. Estes bastões são embalados em sacos de algodão e colocados nos fumeiros, onde são defumados com madeira aromática (SFB, 2013).

Para serem consumidos, os bastões precisam ser ralados. O guaraná em pó pode ser dissolvido em água, como acontece nos rituais indígenas, ou pode ser diluído em suco de frutas frescas. O extrato do guaraná é usado para fazer xaropes, refrescos e bebidas, como o tradicional refrigerante guaraná, que pode ser encontrado em todo o Brasil.

A produção do guaraná no Amazonas tem duas vertentes: o guaraná orgânico e o guaraná híbrido, manipulado nos laboratórios da Empresa Brasileira de Pesquisa Agropecuária - EMBRAPA, que chega às plantações 
para uma larga produção a fim de atender a grande indústria do guaraná nacional, representada pela AMBEv. A produção é baseada na utilização de produtos químicos, agrotóxicos e transgênicos que só atende o aqui e agora, além de prejudicar a saúde dos envolvidos, desde o processo de produção até a própria saúde do consumidor.

Como o guaraná produzido pelos índios nunca teve como princípio a produtividade, nunca foi vantajoso para eles venderem seus produtos para esta grande indústria. Além do guaraná, os indígenas que fazem parte do Projeto Wará também trabalham com outras atividades produtivas.

\section{DA FLORESTA PARA O MUNDO}

Moaci, idealizador do Projeto Wará, empreendeu essa iniciativa há I8 anos. No início era um projeto pequeno que enfrentava muitas dificuldades, mas a comunidade indígena, em contato com o homem branco, precisava fazer alguma coisa, já que, a cada dia que passava, o índio precisava encontrar formas de ganhar dinheiro para sobreviver. Afinal, desde que o dinheiro foi introduzido, a união entre as comunidades já não era mais suficiente para garantir a sobrevivência do povo indígena. Moaci sempre lembra em suas palestras, inclusive na proferida no evento RIO +20 , que "não existe desenvolvimento se não houver uma produção. Seja lá uma família, uma comunidade, um povo ou uma nação. Nesse sentido começamos a criar um comércio justo levando em conta toda a produção que temos dentro da área e da biodiversidade" (RIO + 20, 20I2).

O principal objetivo do projeto era desenvolver uma produção sustentável em harmonia com a natureza no sentido de agregar valor e sensibilizar os consumidores de modo que pudesse ser garantida a produção para as gerações presentes e futuras (CMMAD, 199I). A ideia inicial foi criar um projeto cujo tipo de desenvolvimento fosse duradouro. Moaci ressalta que "não é um projeto de quatro anos, três anos, dois anos, como fazem alguns políticos: sai político, entra político, muda tudo, não é assim. Uma política de desenvolvimento tem que se fazer permanente, para a vida toda". Por isso é que a base do projeto sempre foi a busca pelo fortalecimento das comunidades indígenas. Também há a consciência de 
que esse fortalecimento se dá não somente mantendo os povos indígenas integrados, mas também buscando sensibilizar os consumidores, os exportadores e os distribuidores sobre as características específicas do negócio. Ou seja, conscientizar sobre as diferenças entre os negócios dos índios e do homem branco.

Os indígenas vivem há muito tempo da produção do guaraná e de produtos cultivados na região, mas antes do Projeto Wará, a venda do guaraná não compensava. Existe na região uma importante indústria de bebidas que está disposta a comprar toda a produção do guaraná, a AMBEV. Esta empresa desenvolve, em parceria com a EMBRAPA, um projeto de melhoria genética da semente do guaraná para aumentar a produtividade, assim como habilitam produtores locais para a utilização destas tecnologias, bem como financia estes pequenos produtores.

A história da participação dos índios na comercialização do guaraná orgânico teve início nos anos $70 \mathrm{com}$ a inauguração do Centro de Formação para Trabalhadores Rurais de Anyrá (CETRA). Nos anos 80, o guaraná começou a ser comercializado nas cantinas do primeiro projeto do guaraná em parceria com o Centro de Trabalho Indígena de São Paulo СтI, que tinha por foco "reconhecimento dos direitos territoriais dos povos indígenas, valorização das suas referências culturais e proteção ambiental das suas Terras" (CTI, 2013).

Entretanto, essa experiência regional não atendeu às questões desejadas de sustentabilidade e as comunidades começaram a avaliar a possibilidade da criação de espaços de comercialização no mercado internacional, onde pudessem encontrar o reconhecimento dos compradores internacionais, de modo que viessem contribuir para a preservação e a sobrevivência da etnia indígena, aquela que realmente era a disseminadora da cultura do guaraná. Assim, em 1995, é criado o Projeto Wará, que em parceria com uma instituição de pesquisa do Amazonas, enviou 20 quilos do guaraná em pó ao mercado internacional.

Em 1998, a grande dificuldade da comunidade dos povos indígenas era a organização dos produtores de guaraná. A primeira dificuldade era que as famílias indígenas fossem organizadas como sujeito autônomo 
dentro da sua própria comunidade, denominada Aisó Ayira e no mercado internacional. A segunda era resgatar a cultura indígena e, ao mesmo tempo, gerar renda para a sustentação do projeto.

Foi muito trabalho, pois não bastava vender para o exterior, era necessário sensibilizar a comunidade indígena e os compradores internacionais sobre a proposta de comércio justo baseado em práticas de sustentabilidade ambiental. Em resposta a esse trabalho, no início de 2005, foi implantada a auto-organização com a presença de 70 produtores que protocolaram, de forma participativa, as regras para a produção do guaraná. Esse movimento foi patrocinado pelo Conselho Geral da Tribo Aisó Ayira (CGTAA). Neste mesmo ano, foi discutido e aprovado o novo estatuto do CGTAA.

No ano de 2006, o novo estatuto é executado e um organograma é traçado. É escolhido o secretário de produção e, também, são eleitos o coordenador geral e o tesoureiro pelos próprios produtores das comunidades indígenas.

Em 2008, alguns indígenas resolvem retirar os poderes de representação da maioria e uma minoria reunida na sede do CGTAA resolve modificar o estatuto, dando plenos poderes ao presidente. Mas a maioria não concorda, o que acaba criando um mal estar devido à recusa de alguns de participarem dessa briga. Esta cisão acaba apressando a criação de um Consórcio dos Povos Aisó Ayira (COPOAA). Em 2009, os produtores do guaraná finalmente conseguem se tornar sujeito coletivo autonomamente para impulsionar o projeto integrado do ecodesenvolvimento.

Hoje, I8 anos após sua fundação, o Projeto Wará está despertando o interesse da comunidade acadêmica. A participação da academia ocorre no resgate e apoio à manutenção da cultura do povo Aisó Ayira. O projeto reconhece que os professores que trabalham nas comunidades indígenas são responsáveis pela educação desde a infância até a formação das lideranças e adultos. Entende que a educação precisa ser feita para as comunidades com base na compreensão dos problemas sociais para buscar soluções para o povo indígena. Ensinar a cultura da tribo de respeito ao outro, em que todos se ajudam em busca do bem comum. 


\section{A SEMENTE DA CIÊNCIA OU A SEMENTE SELVAGEM?}

Atualmente, existe grande concorrência na compra do grão do guaraná. É um mercado cuja demanda internacional e nacional superam a oferta. Portanto, existe uma grande disputa entre os compradores pelos produtores.

O concorrente mais importante da produção indígena é uma cooperativa de caboclos, AGROPOMAR, que produz o guaraná orgânico em regime de monocultura. Porém, no começo do Projeto Wará, as relações com a cooperativa não eram de concorrência.

No início do Século xxI, foi criada a APOENA, organização idealizada para unir a produção indígena com a dos agricultores da Cooperativa AGROPOMAR. Esta organização acabou não dando certo devido a problemas de comercialização dos produtos, pois a AGROPOMAR também vendia produto não orgânico.

A Cooperativa AGROPOMAR produz em torno de 60 toneladas, das quais apenas cinco toneladas são certificadas pela ECOCERT. Estas cinco toneladas são exportadas para a empresa Nature Bio, sediada na França. Por outro lado, a produção das comunidades indígenas, em torno de cinco a seis toneladas, é toda orgânica.

O consórcio dos povos indígenas exporta guaraná e produtos naturais somente para importadores que tenham compromisso com o comércio justo e solidário. São quatro os distribuidores que comercializam produtos controlados pelos produtores Aisó Ayira por meio do Consórcio: Guará Tropical, Aтв Altromercato, Cooperativa Amazônia Livre e Healthy Food. No Brasil, o consórcio não possui distribuidor autorizado, realizando ele mesmo suas vendas apenas por meio da internet.

Todavia, cabe precisar que os produtores associados ao consórcio possuem o direito de vender produtos a quem desejar, pois algumas vezes isso é necessário devido à urgência monetária. Entretanto, quando isso acontece, o consórcio não se responsabiliza pelo controle de qualidade do produto e da ética nas transações.

São três as certificações obtidas pelos indígenas: I. Ministério da Agricultura Familiar - Certificação Nacional; 2. Instituto Biodinâmico (IBD); 3. Forest Garden Products Certification (FGP) - essa é uma certificação Internacional do Sri Lanka aceita na Europa, Índia e Tailândia. 
Os produtores associados à cooperativa recebem mais do que se produzissem para a grande indústria do Guaraná. Assim, tanto a cooperativa quanto os produtores do consórcio indígena têm incomodado bastante a grande indústria do guaraná. Porém, como a AGROPOMAR e outros produtores da região que produzem o guaraná orgânico o fazem em regime de monocultura, o preço destes produtores tem caído bastante no mercado. A tendência do mercado é também tentar baixar o preço dos orgânicos indígenas, mas que em virtude da especificidade da produção, baixar ainda mais o preço pode não ser economicamente viável, assim como alterar as formas de produção pode levar ao desvirtuamento das práticas de sustentabilidade. 


\section{NOTAS DE ENSINO}

\section{NATUREZA DO CASO}

O caso descrito ilustra o dilema entre a possibilidade de ampliação de atividade econômica, tendo como pano de fundo os negócios internacionais e questões éticas e culturais, que levam em consideração não somente a sustentabilidade econômica, mas a ambiental e a social. Portanto, tratase de uma história complexa, incorporando elementos de várias áreas do conhecimento, e podendo ser analisada sob as óticas da estratégia internacional, desenvolvimento sustentável, ética e organização social.

Do ponto de vista da organização social e ética, descreve o momento organizativo em que as comunidades indígenas e cabocla são sensibilizadas, não somente para a necessidade de trabalhar em cooperação, mas também em relação ao imperativo de atuar economicamente de modo responsável, respeitando as pessoas, a natureza e a cultura do povo da floresta. Ainda descreve a luta de grupos menos favorecidos contra a grande indústria do guaraná que, além de não respeitar os limites da natureza, tem comportamento monopolizador e autoritário no sentido de não permitir mecanismos da livre economia de mercado para a definição dos preços.

No aspecto da estratégia internacional, é particularmente inovador, pois descreve a inserção do grupo na economia internacional ao se beneficiar da sua condição enquanto povo da floresta que empunha a bandeira do respeito à cultura do povo e do respeito às pessoas e à natureza, uma vez que é um mercado consumidor que reivindica um comportamento sustentável e ético de todo o planeta.

Em relação ao desenvolvimento sustentável, a descrição do caso revela que a iniciativa indígena e dos caboclos é uma alternativa à produção em massa que, além de pressupor o respeito à natureza e às pessoas, é altamente rentável economicamente. Portanto, o caso procura revelar as estratégias utilizadas pelo Conselho Geral da Tribo para conseguir aumentar a sua produção e permanecer em um mercado altamente exigente e rentável, que é o mercado internacional. 


\section{OBJETIVOS DE APRENDIZAGEM}

Este caso tem como alvo estudantes de cursos de administração ou áreas afins que estejam matriculados em cursos de graduação ou pós-graduação. É recomendado para ser utilizado em disciplinas de estratégia internacional, desenvolvimento sustentável e gestão social e ambiental.

O principal objetivo do caso de ensino é relacionar as estratégias de internacionalização com o desenvolvimento sustentável. Os estudantes devem ser estimulados a identificar na literatura as possibilidades das estratégias de internacionalização em atividades que tenham suas estratégias de negócios baseadas em tendências globais como o tratamento justo e ético da natureza e das populações mais pobres.

No tocante à abordagem sobre internacionalização, o objetivo é destacar a forma de entrada em mercados internacionais dessas atividades, que são alternativas ao modelo de mercado vigente.

Quanto ao aspecto do desenvolvimento sustentável, o objetivo é identificar as preocupações e as ações necessárias para a consecução de um negócio ambientalmente sustentável, socialmente justo e economicamente viável, bem como as exigências dos consumidores em relação a tais negócios. 


\section{ANÁLISE DO CASO}

\section{MODOS DE ENTRADA EM MERCADOS INTERNACIONAIS}

Existem algumas questões que podem facilitar a comercialização dos produtos orgânicos no mercado internacional, bem como outras que podem comprometer ou dificultar a entrada no referido mercado.

Em relação à facilidade, está a tendência de mercado dos países desenvolvidos em buscar cada vez mais produtos que sejam ambientalmente sustentáveis e socialmente justos. Além disso, existe também uma tendência à valorização dos produtos orgânicos provenientes da Floresta Amazônica, em função da riqueza de sua biodiversidade e sua importância para toda a humanidade.

Do ponto de vista dos elementos complicadores, colocam-se as exigências de certificação para os produtos orgânicos, bem como os requisitos de importação desses produtos que são menos elementares em função dessa característica e as supostas dificuldades em lidar com o mercado estrangeiro.

Nesse sentido, é salutar levar os estudantes a identificar e analisar o modo de entrada eleito pelo projeto, bem como discutir suas vantagens e desvantagens, com base na Figura I, a seguir.

Para tanto, é possível contar com o artigo de Pan e Tse (2000) intitulado Hierarchical Model of Market Entry Modes (Modelo Hierárquico de Modos de Entrada no Mercado). 
Figura I Modos de entrada no mercado internacional

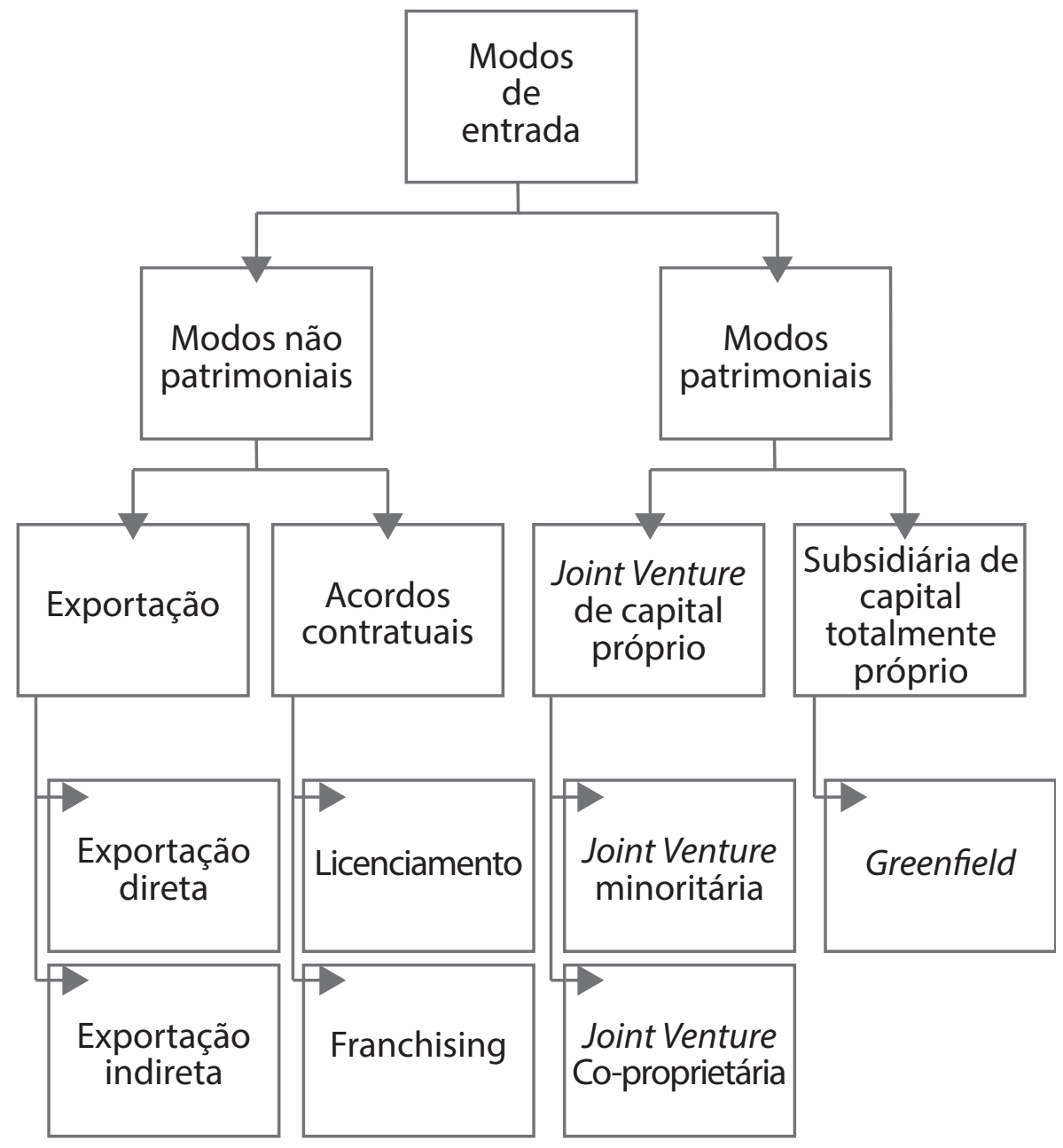

Outro aspecto a discutir e analisar seriam as prováveis futuras mudanças no modo de entrada atual, considerando as vantagens e desvantagens. Para tanto, é possível contar com o apoio do artigo de Benito, Petersen e Welch (2009), cujo título é Towards more realistic conceptualizations of foreign operation modes.

A Figura 2, a seguir, ilustra os elementos que devem ser considerados na análise. Por outro lado, é importante lembrar que esse será apenas um 
exercício de criatividade e levantamento de possibilidade sobre os caminhos futuros dos negócios internacionais para o grupo de empreendedores.

Figura 2 Modos de operações internacionais

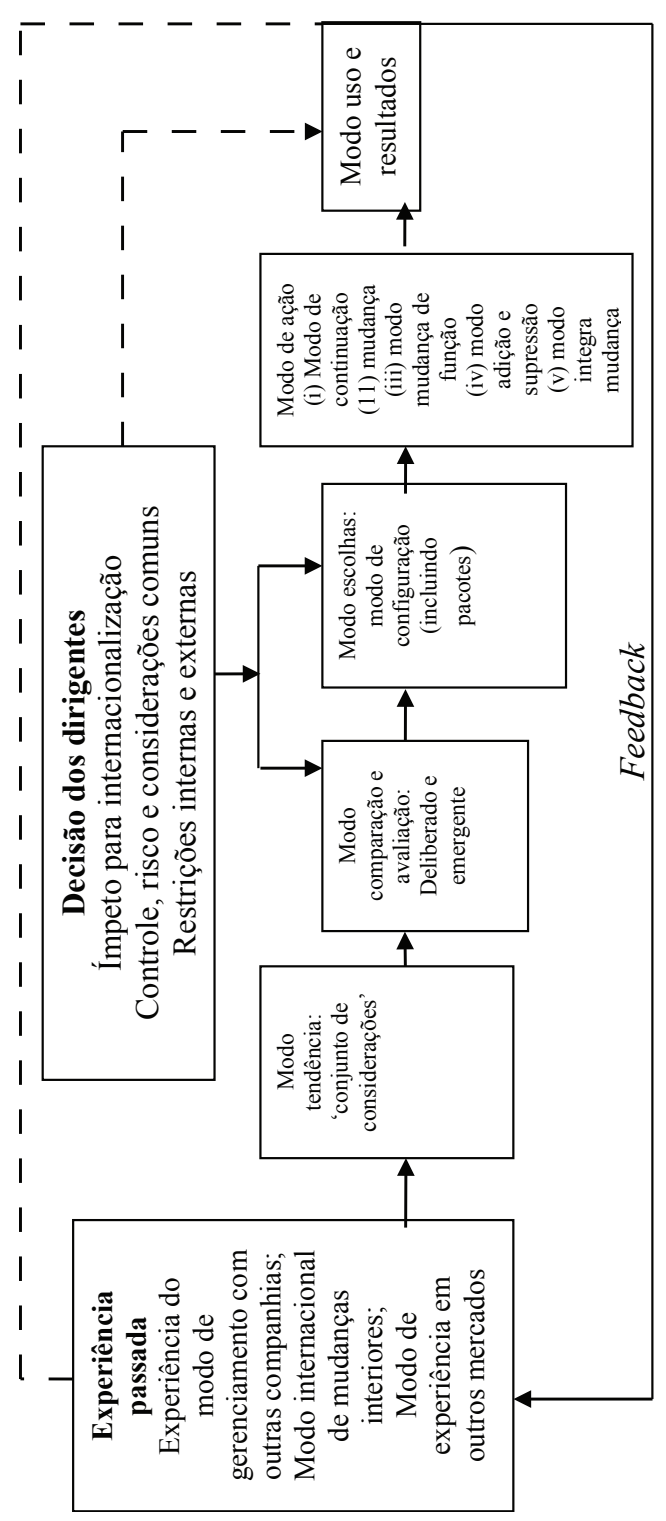

Fonte: Benito, Petersen e Welch (2009). 


\section{QUESTÕES PARA DISCUSSÃO}

1 Como a comunidade indígena produtora do Guaraná poderá se proteger da concorrência que oferece um produto semelhante a um custo menor?

2 Que modos de entrada no mercado internacional seriam adequados para o consórcio dos povos Aisó Ayira?

3 Quais dificuldades estão relacionadas ao comércio justo?

4 Como tornar produtos orgânicos competitivos comercialmente?

5 Qual a diferença no modo de produção dos povos indígenas e da cooperativa dos caboclos para o modo de produção da grande indústria que produz guaraná?

\section{ADMINISTRAÇÃO ESTRATÉGICA E VANTAGEM COMPETITIVA}

Considerando as especificidades do produto e da condição organizativa do grupo, é salutar pensar em levar os estudantes a aplicar o modelo da visão baseada em recursos que pode ser encontrada em Administração Estratégica e Vantagem Competitiva de Barney e Hesterly (2007). Os autores partem da noção do modelo vRIO, que consiste em "um modelo integrador, amplo o bastante para ser aplicado na análise de grande variedade de casos e cenários de negócios; mas, suficientemente simples para ser compreendido e compartilhado" (BARNEY; HESTERLY, 2007, p. I3).

Além da proposta do modelo integrador que analisa a empresa do ponto de vista dos recursos enquanto o seu valor, raridade, imitabilidade e organização, os autores também buscam integrar as questões estratégicas das empresas com os requisitos éticos de uma sociedade em transformação e crise constante, assim como a inserção de organizações no mercado internacional. Nesse sentido, suas preocupações éticas ao perpassarem o atendimento das necessidades/satisfação dos shareholders e stakeholders, o bem estar da sociedade mediante a busca das empresas por vantagem competitiva e a solução para questões de externalidades deixam evidente uma tendência de solução desses dilemas por meio das leis de mercado e da livre iniciativa, que vai ao encontro das propostas de sustentabilidade que não desprezam o caráter da viabilidade econômica e financeira dos 
negócios nem a possibilidade de atuação em mercados fora das fronteiras nacionais.

Portanto, tal abordagem é essencial para mostrar que grande parte do êxito dos negócios no mercado internacional está relacionada às características dos produtos (valor, raridade e imitabilidade) e a capacidade organizativa dos índios que se encontra especialmente dispersa e representando situação alternativa em relação à grande empresa capitalista.

Ainda considerando a pauta das vantagens estratégicas, outros enfoques que podem ser abordados são os frameworks apresentados nos trabalhos de autores que discutem a Responsabilidade Social Corporativa Estratégia. Nesta perspectiva é possível citar os trabalhos de Zadek (2004), Carroll (1979; 1999), Husted e Salazar (2006), e Porter e Kramer (2006).

Para Zadek (2004), o grande desafio das organizações é empreender práticas responsáveis de negócios. Neste intento, as organizações passam por, pelo menos, cinco fases perceptíveis de atuação em relação às suas responsabilidades. Mas, além disso, assim como as organizações, a sociedade também amadurece sua visão sobre a forma como as organizações devem tratar este problema.

Segundo o autor, quando as organizações começam a desenvolver senso de responsabilidade, elas passam pelos seguintes estágios:

1 Defensivo: as organizações apenas procuram se defender dos ataques à sua reputação.

2 Condescendente: as organizações passam a observar bases políticas e legais dos custos do fazer negócio para reduzir a erosão do valor econômico no médio prazo e também para não manchar sua reputação e evitar riscos de reivindicações de ativistas.

3 Gerencial: as organizações começam a se envolver com os problemas sociais, mas o objetivo disso é mitigar a erosão do valor econômico da empresa no médio prazo e no longo prazo e obter ganhos por inserir práticas de responsabilidade aos negócios.

4 Estratégico: as organizações implantam ações para lidar com problemas sociais no objetivo estratégico dos negócios. O objetivo dessas práticas é aumentar o valor econômico no longo prazo e ganhar vantagem 
competitiva com a inovação.

5 Civil: as organizações passam a promover ações coletivas relacionadas com preocupações da sociedade que podem, algumas vezes, estar ligadas diretamente à estratégia da empresa.

A questão da sustentabilidade ambiental insere-se nessa discussão, pois o autor lembra que muitas questões que antes não preocupavam a sociedade, atualmente, aparecem nas pautas de reivindicações, e um exemplo disso é a preocupação com o futuro do planeta diante da crescente degradação do ambiente natural. Portanto, o autor ensina que o truque para sobreviver a essas mudanças é as empresas procurarem prever e responder com credibilidade a essas mudanças de consciência da sociedade, embora também reconheça que essa pode ser uma tarefa difícil.

Para mensurar o grau de maturidade dos problemas sociais e a expectativa pública em torno dele, Zadec (2004) apresenta uma escala adaptada da indústria farmacêutica Novo Nordisk que considera os seguintes estágios de maturidade: latente, emergente, consolidado e institucionalizado.

Considerando essas duas escalas, Zadek (2004) desenvolve uma ferramenta denominada de aprendizagem civil, que permite o cruzamento dos dois tipos de aprendizagem (organizacional e social) e orientar a empresa sobre a melhor estratégia a ser adotada. Do cruzamento desses dois estágios de aprendizagem, qualquer empresa pode identificar em que zona se encontra. 
Figura 3 Ferramenta de aprendizagem civil

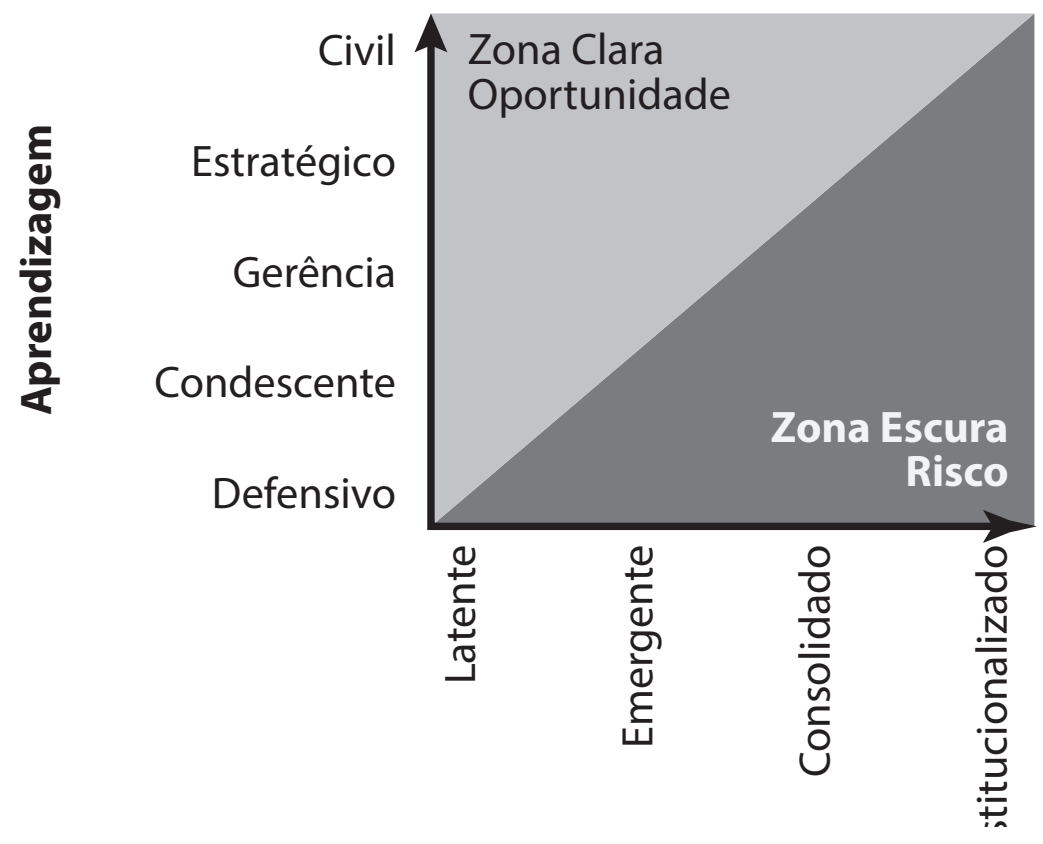

Fonte: Zadek (2004).

Portanto, o uso da ferramenta é capaz de revelar o ponto em que a organização pode transformar a zona de risco vermelha na zona verde de oportunidade, mas para tanto, a organização precisa estar atenta às demandas da sociedade.

A análise das características de atuação estratégica das organizações em relação a sua responsabilidade social, também pode ser discutida baseada em Carroll (1979), que também usa uma tipologia para ressaltar as várias obrigações das organizações. Para o autor, as organizações devem se preocupar com os aspectos econômicos, legais, éticos e discricionários. A Figura 4 ilustra como o autor visualiza essas quatro formas de atuação das corporações: 
Figura 4 Tipos de Responsabilidade Social

\section{Responsabilidade Discricionária}

\section{Responsabilidade Ética}

\section{Responsabilidade Legal}

\section{Responsabilidade Econômica}

Fonte: Baseado em Carrol (1979, p. 40).

Os quatro componentes da RSC começam propondo que o desempenho econômico é a base de tudo. Ao mesmo tempo, espera-se que o negócio obedeça as leis e comportamentos da sociedade. A seguir, o negócio deve ser ético em seu nível mais fundamental e expressar a obrigação de fazer o que é certo, justo e equitativo para evitar ou minimizar os danos às partes interessadas (trabalhadores, consumidores, meio ambiente, e outros). Finalmente, espera-se que a organização seja uma boa cidadã, em que se espera que as organizações colabora com recursos humanos e financeiros para melhorar a qualidade de vida das pessoas.

O comportamento estratégico da organização indígena também pode ser abordado com base em Husted e Salazar (2006). Os autores também usam 
uma tipologia em que classificam o comportamento das organizações de Altruísta, Egoísta e Estratégico. Partem principalmente da premissa de que é impossível maximizar em mais de uma dimensão (lucro e social) ao mesmo tempo, pois existe trade-off entre lucros e desempenho social. Entretanto, é ponto de exceção, o fato de ambos alcançarem essa condição ao mesmo tempo: o investimento em projetos sociais corporativos precisa contribuir para a maximização do lucro.

O modelo apresentado pelos autores, portanto, considera que o lucro e o bem estar da sociedade podem ser alcançados de várias formas, mas é somente por meio da atuação responsável estratégica que tanto a sociedade quanto a corporação podem obter os melhores resultados. É na responsabilidade estratégica que se justifica a preocupação com a sustentabilidade, uma vez que assim a organização realiza algum benefício adicional (boa reputação, diferenciação de produto, preço Premium, etc.) que gera um lucro maior do que o normalmente esperado.

Por sua vez, Porter e Kramer (2006) propõem um modelo de responsabilidade social corporativa que pressupõe dois tipos de ações: uma responsiva - como uma reação aos clamores da sociedade - e outra estratégica - alinhadas ao planejamento estratégico da empresa.

Os autores consideram que a RSC tem sido a prioridade para os empresários líderes, em todo o mundo, na primeira década do século XXI. No entanto, eles veem que as estratégias usadas na RSC nas corporações estão fora de sintonia dos negócios perdendo, em consequência, ótimas oportunidades que poderiam ser revertidas, inclusive para a sociedade.

Neste sentido, o princípio da sustentabilidade suscita o interesse da corporação usando uma base tripla formada pelo econômico, social e ambiental e, ainda, de longo prazo.

Outro ponto que deve ser considerado é a atuação na cadeia de valor, que pode ser feita de modo que melhore a dimensão social envolvida, ao mesmo tempo, que investimentos no setor competitivo aumentam o valor da cadeia produtiva.

As organizações que levam em consideração essas questões em suas decisões ficarão cada vez mais separadas dos seus concorrentes. Uma vez que a mais 
importante função da organização é contribuir para uma economia próspera.

Os autores também consideram que seria apropriado substituir a RSC pela Integração Social da Corporação (ISC). Nesta perspectiva, é importante salientar que as organizações não são responsáveis por todos os problemas do mundo e também não possuem recursos para solucionar a todos, mas que criar um valor compartilhado (com a sociedade) em um determinado problema, resultará em diferencial competitivo (em relação à concorrência). Assim, a organização poderá causar impacto social maior do que qualquer outra instituição ou organização filantrópica.

\section{QUESTÕES PARA DISCUSSÃO}

1 Quais as características do produto e da organização dos Aisó Ayira, baseadas no modelo de Barney e Hesterly (2007), que apontam para o fracasso e/ou sucesso na inserção do negócio no mercado internacional?

2 Como a estratégia de comercialização de produtos orgânicos, baseada em práticas de comércio justo, pode ser analisa à luz da literatura sobre RSC?

3 Em qual zona se encontra a organização dos Aisó Ayira quando considerada para análise da ferramenta de aprendizagem civil proposta por Zadel (2004)? Justifique sua resposta.

\section{NEGÓCIO ECONOMICAMENTE RENTÁVEL, AMBIENTALMENTE SUSTENTÁVEL E SOCIALMENTE JUSTO}

Considerando os pilares fundamentais do negócio que está sendo estudando, é imprescindível que os estudantes sejam levados a refletir sobre suas condições de sustentabilidade e se ele está de fato contribuindo para o desenvolvimento sustentável da região e do planeta.

Para tanto, pode-se partir de Sachs (1993) que, percebendo que a sustentabilidade alcança diversos setores, sugeriu que houvesse uma sistematização em cinco dimensões: a social, a econômica, a cultural, ecológica e a dimensão espacial. Baseado na dimensão social, Sachs (r993) evidencia que, para conquistarmos a qualidade de vida, se faz necessário ocorrer quebra de paradigmas existentes a fim de se formar sociedades equitativas na geração de oportunidades e na distribuição de renda e de bens. A sustentabilidade 
econômica pressupõe o aumento da produção e da riqueza social mundial sem dependência externa por meio da alocação e gestão mais eficiente dos recursos e por um fluxo regular de investimentos públicos e privados, pressupondo-se autonomia na geração e disseminação do conhecimento por intermédio da pesquisa cientifica e tecnológica. A dimensão ecológica defende a geração e a disseminação de tecnologias limpas, além da criação e consolidação de mecanismos de proteção ambiental. Nesse aspecto, Sachs (I993) julga essencial a promoção de mudanças no padrão de consumo da sociedade, não apenas a limitação desse consumo, mas também a valorização dos produtos gerados em processos que contribuem para o equilíbrio ambiental. A dimensão cultural da sustentabilidade encontra-se relacionada ao respeito das especificidades de cada local, valorizando a cultura regional. Na busca por modelos de desenvolvimento, deve-se prezar pela pluralidade de soluções e pela valorização da diversidade das culturas locais. Por sua vez, a dimensão espacial referese a uma adequada distribuição demográfica sobre o planeta por meio de uma nova configuração rural-urbana que possibilite, de forma equilibrada, a redução da concentração populacional e de suas atividades econômicas nos grandes centros urbanos, podendo assim proteger ecossistemas mais frágeis e praticar atividades da zona rural em escalas menores e com técnicas que se mantenham.

Outra análise, mais simples, que pode dar lugar a essa é a baseada no trabalho de Elkington (2012), que apresenta sua análise em três pilares comumente reconhecidos como The Triple Bottom Line, que discute apenas os aspectos econômicos, sociais e ambientais.

\section{QUESTÕES PARA DISCUSSÃO}

1 De que forma o relacionamento da organização com a natureza e as pessoas tem contribuído para o sucesso dos negócios?

2 Existe um limite para o tamanho do negócio que o permita continuar contribuindo para a sustentabilidade?

3 Até que ponto fica comprometida a sustentabilidade do negócio quando o que está em jogo é o comércio internacional, ou seja, que pressupõe o deslocamento dos produtos para diversas partes do globo? 


\section{QUESTÕES PRÉVIAS}

A utilização das questões prévias é uma prática que tem sido utilizada para instigar a curiosidade dos alunos em relação ao tema e ao caso que será apresentado. Nesse sentido, apresentam-se algumas questões que podem auxiliar o docente neste objetivo de prender a atenção do aluno, quais sejam:

1 É possível um negócio ser ambientalmente sustentável e socialmente justo e ainda ser rentável?

2 Quais seriam as principais dificuldades e facilidades, do ponto de vista organizativo, que um grupo de caboclos e índios da Amazônia poderia encontrar para comercializar seus produtos orgânicos no mercado internacional?

3 Quais seriam os principais desafios a serem enfrentados pelos caboclos e indígenas para a comercialização dos seus produtos orgânicos no mercado internacional? Como superar esses desafios?

4 A oferta de guaraná orgânico pode ser incompatível com os princípios da sustentabilidade?

5 É possível um "verdadeiro" desenvolvimento sustentável? 


\section{PLANO DE AULA}

No Quadro I é apresentado uma sugestão de plano de aula de três horas de duração. Ressalte-se que a proposta abaixo deve ser adaptada à necessidade do docente em função dos objetivos do Plano de Ensino da disciplina.

Quadro I Plano de aula - Duração de 3 horas

\begin{tabular}{|c|c|c|}
\hline Tempo & Atividade & Recursos \\
\hline $0-10 \mathrm{~min}$ & $\begin{array}{l}\text { Identificar nos alunos qual o nível de } \\
\text { conhecimento deles sobre mercados } \\
\text { internacionais, produção de produtos } \\
\text { orgânicos e desenvolvimento sustentável }\end{array}$ & $\begin{array}{l}\text { Perguntas sobre o conhecimento } \\
\text { anterior dos alunos sobre os temas }\end{array}$ \\
\hline $10-25 \min$ & Desenvolver nos alunos interesse pelo caso & $\begin{array}{l}\text { Lista de perguntas sugeridas no item } \\
\text { Questões Prévias }\end{array}$ \\
\hline $25-50 \mathrm{~min}$ & Apresentar os conceitos a serem abordados & $\begin{array}{l}\text { Textos sugeridos no item Análise do } \\
\text { Caso } \\
\text { Quadro e projetor }\end{array}$ \\
\hline $50-75 \mathrm{~min}$ & $\begin{array}{l}\text { Ler o caso (a ser feito em grupos de três a } \\
\text { cinco alunos) }\end{array}$ & $\begin{array}{l}\text { Texto de apoio com o caso: Guaraná } \\
\text { Orgânico: Ecodesenvolvimento e } \\
\text { Comércio Justo }\end{array}$ \\
\hline $75-95 \mathrm{~min}$ & $\begin{array}{l}\text { Discutir em subgrupo as questões } \\
\text { propostas pelo professor }\end{array}$ & $\begin{array}{l}\text { Perguntas apresentadas no item } \\
\text { Análise do Caso }\end{array}$ \\
\hline $95-105 \mathrm{~min}$ & Intervalo & \\
\hline $105-150 \mathrm{~min}$ & $\begin{array}{l}\text { Discutir em plenária com moderação dos } \\
\text { participantes pelo professor }\end{array}$ & Sala em círculo \\
\hline $\begin{array}{l}150-180 \\
\min \end{array}$ & $\begin{array}{l}\text { Apresentar síntese das principais relações } \\
\text { teórico-práticas identificadas no estudo do } \\
\text { caso em sala }\end{array}$ & Quadro e pincel \\
\hline
\end{tabular}




\section{AVALIAÇÃO DA APRENDIZAGEM}

Recomenda-se que a participação na sala, nos grupos de trabalho e nas discussões em plenária, a leitura do material relacionado e as respostas às questões previamente entregues venham compor os múltiplos critérios que podem ser utilizados para a definição do quadro de avaliação.

Sugere-se ainda que parte da avaliação escrita seja uma síntese de toda a discussão, que pode ser desenvolvida na própria sala de aula após os trabalhos ou, em casa, para que se possibilite outra imersão no caso e nos materiais que previamente devem ter sido estudados. 


\section{CONSIDERAÇÕES FINAIS}

Por fim, é importante salientar que as possibilidades de abordagem do caso em disciplinas como Desenvolvimento Sustentável, Estratégia Internacional, Gestão Social e Ambiental, não se esgota aqui.

Exemplo disso é a possibilidade de aplicação do caso também à teoria dos Stakeholders de Freeman (2005). Ainda como sugestão de plano de aula para o emprego desse framework, como o caso envolve múltiplos stakeholders, é de que os alunos sejam divididos em vários grupos que representam os stakeholders (Organização Aisó Ayira, cooperativa de caboclos, índios, a concorrência, o comprador internacional, o governo, a comunidade local, etc.), de forma que cada um defenda seus interesses, façam movimentos de pressão, proponham eventuais acordos, etc. 


\section{REFERÊNCIAS}

BARNEY, J.B; HESTERLY, W.S. Administração Estratégica e Vantagem. São Paulo. Pearson, 2007.

BENITO, G.R.G.; PETERSEN, B.; WELCH, L.S. Towards more realistic conceptualizations of foreign operation modes. Journal of International Business Studies, v. 40, n.1, p. 1455-1470, 2009.

CARROLL, A.B. A three-dimensional conceptual model of corporate performance. The Academy of Management Review, v. 4, n. 4, p. 497-505, 1979.

CARROLL, A.B. Corporate social responsibility. Business and Society, v. 38, n. 3, p. 268 -295, 1999.

\section{COMISSÃO MUNIDAL SOBRE MEIO AMBIENTE E DESENVOLVIMENTO}

SUSTENTÁVEL (CMMAD - 1987). Nosso Futuro Comum. Rio de Janeiro: FGV, 1991.

ELKINGTON, J. Sustentabilidade, Canibais com Garfo e Faca. São Paulo: Makron Books, 2012.

FREEMAN, R.E. Stakeholder Theory of the Modern Corporation. In: Shari CollinsChobanian (Ed.). Ethical Challenges to Business as Usual. New Jersey: Pearson Prentice Hall, 2005.

HUSTED, B.W.; SALAZAR, D.J. Taking Friedman seriously: Maximizing profits and social performance. Journal of Management Studies, v. 43, n.1, p. 75-91, 2006.

PAN, Y.; TSE, D.K. The Hierarchical Model of Market Entry Modes. Journal of International Business Studies, v. 31, n. 1, p. 535-554, 2000.

PORTER, M.; KRAMER, M. Strategy \& Society: The Link Between Competitive Advantage and Corporate Social Responsibility. Harvard Business Review, v. 84, n.12, p. 78-92, 2006.

SACHS, I. Estratégias de Transição para o século XXI - desenvolvimento e meio ambiente. São Paulo: Studio Nobel Fundap, 1993.

SLOW FOOD BRASIL (SFB). Fortalezas Slow Food no Brasil. Disponível em: <http:// www.slowfoodbrasil.com/fortalezas/fortalezas-no-brasil/> Acesso em: 02/07/2013.

UNITED NATIONS CONFERENCE ON SUSTAINABLE DEVELOPMENT. Cúpula dos Povos pela justiça social e ambiental. Entrevista de Moaci Batista Garcia na RIO + 20. Disponível em <http://www.youtube.com/watch?v=mIM3t4tdYE0 > Acesso em: 20/12/2012.

ZADEK, S. The path to Corporate responsibility. Harvard Business Review, v. 82, n. 12, p. 125-136, 2004.

* Os nomes de pessoas e instituições foram permutados por outros fictícios visando manter a privacidade dos mesmos. 


\section{DADOS DOS AUTORES}

ADRIANA TEIXEIRA BASTOS`adriana@ead.uece.br

Doutoranda em Administração pela Universidade de Fortaleza

Instituição de vinculação: Universidade Estadual do Ceará

Fortaleza/CE - Brasil

Áreas de interesse em pesquisa: Desenvolvimento Sustentável, Cooperação e

Institucionalismo.

*Av. Paranjana, 1700 Serrinha Fortaleza/CE 60.714-903

CORA FRANKLINA DO CARMO cora.franklina@uece.br

Doutoranda em Administração pela Universidade de Fortaleza

Instituição de vinculação atual: Universidade Estadual do Ceará

Fortaleza/CE - Brasil

Áreas de interesse em pesquisa: Comportamento do consumidor, Estratégia e

Responsabilidade Social e Ambiental.

FÁTIMA REGINA NEY MATOS fneymatos@unifor.br

Doutora em Administração pela UFPE

Instituição de vinculação: Universidade de Fortaleza

Fortaleza/CE - Brasil

Áreas de interesse em pesquisa: Estudos organizacionais e metodologia qualitativa.

MÁRIO HENRIQUE OGASAVARA mario.ogasavara@espm.br

Doutor em Administração pela University of Tsukuba (Japão)

Instituição de vinculação: Escola Superior de Propaganda e Marketing

São Paulo/SP - Brasil

Áreas de interesse em pesquisa: Internacionalização de Empresas e Estratégias Globais. 